"This is the pre-peer reviewed version of the following article: Dan Wen and Alexander Eychmüller (2016). Enzymatic Biofuel Cells on Porous Nanostructures. Small. Special Issue: Advances in Nanobiotechnology, Volume 12, Issue 34, September 14, 2016, Pages 4649-4661, which has been published in final form at DOI: 10.1002/smll.201600906.

This article may be used for non-commercial purposes in accordance with Wiley Terms and Conditions for Self-Archiving."

\title{
Enzymatic Biofuel Cells on Porous Nanostructures
}

Dan Wen and Alexander Eychmüller*

Dr. D. Wen, Prof. A. Eychmüller

Physical Chemistry, TU Dresden

Bergstrasse 66b, 01062 Dresden, Germany

E-mail: alexander.eychmueller@chemie.tu-dresden.de

Keywords: enzymatic biofuel cells, porous nanostructures, bioelectrocatalysis

\begin{abstract}
Biofuel cells (BFCs) that utilize enzymes as catalysts represent a new emerging source of sustainable and renewable energy. Numerous efforts have been directed to improve the performance of the enzymatic BFCs (EBFCs) with respect to power output and operational stability for further applications in portable power sources, self-powered electrochemical sensing, implantable medical devices, etc. This concept article details the latest advances in the EBFCs based on porous nanoarchitectures over the past 5 years. Porous matrices from carbon, noble metal, and polymer promote EBFCs development through the electron transfer and mass transport benefits. We will also discuss some key issues on how these nanostructured porous media improve the performance of EBFCs in the end.
\end{abstract}

\section{Introduction}

Biofuel cells (BFCs) belong to a special kind of fuel cells where biocatalysts such as enzymes and microorganisms are employed as the catalysts and biomass as the fuels. ${ }^{[1]}$ Compared to conventional fuel cells, BFCs are low-cost and active in moderate conditions (e.g. room 
temperature and neutral $\mathrm{pH}$ ) and therefore viewed as a potential green energy technology. ${ }^{[2]} \mathrm{In}$ particular, enzymatic BFCs (EBFCs) can be formatted into portable power sources and implantable medical devices due to the facile miniaturization and higher power densities they typically possess, in contrary to microbial BFCs. ${ }^{[3]}$ The first EBFC has been pioneered by Yahiro, Lee, and Kimble in 1964, which used glucose oxidase (GOx) as the anodic catalyst and glucose as the biofuel. ${ }^{[4]}$ Since then, considerable efforts have been put on EBFCs for gaining high power output and good operational stability for their potential applications. ${ }^{[5]}$ Some outstanding examples are available in the application field of EBFCs for self-powered biosensors, implantable medical devices, and portable power sources, etc. Katz and Willner invented the concept of self-powered biosensors that utilized BFC as a biosensor for the fuel. ${ }^{[6]}$ The first BFC operating in a living organism was the work of Mano and Heller who implanted their glucose $/ \mathrm{O}_{2}$ cell in a grape. ${ }^{[7]}$ Sony company announced an EBFC that can be linked in sequence and used to power mp3 player. ${ }^{[8]}$ Although numerous efforts have been devoted to the development of EBFCs, they are not currently in use outside of the laboratory. Still, two critical issues concerning low power density and short lifetime being dependent on enzyme stability, electron transfer rate, enzyme loading, and fuel/oxidant mass transport are needed to be addressed before EBFCs become really competitive in practical applications. ${ }^{[9]}$

EBFCs relay on enzymatic bioelectrocatalysis, where electron transfer occurs between the enzyme and the electrode directly (DET) or via a redox mediator (MET). Recent progress in nanobioelectrocatalysis on the basis of novel nanostructures shows great promise to solve the above concerned issues and thus makes the actual applications possible. ${ }^{[10]}$ The incorporation of nanomaterials can increase the enzyme loading and facilitate reaction kinetics, thus improve the power density of BFCs. ${ }^{[11]}$ In addition, research efforts have also been made to advance the activity and stability of immobilized enzymes by using nanostructures. ${ }^{[12]}$ Among various types of nanostructures, porous substrates with three-dimensional (3D) structure and high porosity are a promising choice. Generally, micro- and mesopores provide high surface 
areas while macropores guarantee accessibility to the surface. ${ }^{[13]}$ In this respect, porous nanostructures are endowed with additional remarkable features for the purpose of the EBFCs development. The larger surface area can ensure the immobilization of large amounts of enzymes and corresponding reagents (co-factors, mediators) if needed, and increase the reactive surface area. ${ }^{[14]}$ The pores being large enough allow for easy permeation of the electrolyte and oxidant, and support fuel transport to the catalyst reaction sites. ${ }^{[15]}$ Inspired by the enhanced electron transfer and mass transport abilities, it appears to be reasonable to expect that achievements in porous nanostructured biocatalysts will play a critical role in overcoming the major obstacles for the development of powerful EBFCs. ${ }^{[16]}$

Rather than giving a comprehensive review of the topic, here we intend to provide an overview of the recent advances in the field of EBFCs enhanced by porous nanoarchitectures over the past 5 years. It will mainly consider porous structures from carbon materials including carbon nanotubes, graphene, and porous carbon, as well as noble metal and polymeric materials used as electrode materials and enzyme immobilization matrices to develop high performance BFCs. In addition, a discussion on how porous nanoarchitectures work on EBFCs will be included.

\section{Porous Carbon Nanostructures based EBFCs}

\subsection{Carbon Nanotubes}

Carbon nanotubes (CNTs) came into the focus of considerable research fields since their discovery by Iijima in $1991 .^{[17]}$ Specifically, coupling the unique electronic and structural properties of CNTs with the catalytic features of enzymes, CNTs thus offer tremendous opportunities for the development of high performance EBFCs. ${ }^{[18]}$ They can not only be used as a support for a high loading and dispersion of enzymes on the electrode due to their ability to assemble in large porous and conductive networks, but also they facilitate electron transfer between enzyme and electrode via a MET and/or DET way. Dong et al. firstly presented work 
on the fabrication of a glucose/ $\mathrm{O}_{2} \mathrm{EBFC}$ with a $\mathrm{pH}$-dependent power output based on $\mathrm{GOx}$ and laccase entrapped CNTs bioelectrodes coupled with a porous carbon matrix ${ }^{[19]}$ However, a perfluorinated membrane is required to separate the anodic and cathodic compartments due to the free dispersed mediators. Thereafter Mao and co-authors demonstrated a single-walled CNTs-based one-compartment glucose $/ \mathrm{O}_{2} \mathrm{BFC}$ with a high open circuit voltage (OCV) of 0.8 V. The CNTs played a role as a support for an anodic biocatalyst (glucose dehydrogenase, GDH) as well as redox mediator for the oxidation of glucose, and also for facilitating the DET of the cathodic catalyst (laccase) for the reduction of $\mathrm{O}_{2}$. The power output of the cell is only $9.5 \mu \mathrm{W} \mathrm{cm}{ }^{-2}$, which is probably due to the slow mass transport at the planar electrodes. ${ }^{[20]}$

Since then, tremendous research on CNTs-based EBFCs has been performed for improving the operational performance. ${ }^{[21]}$ Most of the cases involve a simple dispersion of CNTs on planar electrode surfaces, which form quite dense structures and limit electron transfer and especially mass transport, and thus the poor power density of the early CNTs-based EBFC configurations. It is efficient to fabricate more porous electrode materials of CNTs for powerful BFC constructions. For example, as a new member of the CNT family, single-walled carbon nanohorn have been employed to build BFCs with an improved power density and stability. ${ }^{[22]}$ The enhanced performance could be attributed to a considerable capacity of micropores and a little mesoporosity originating from the hexagonal stacking. ${ }^{[23]}$ In addition, 3D porous CNTs bioelectrodes prepared by a layer-by-layer assembly technique were used to fabricate EBFCs. ${ }^{[24]} \mathrm{A}$ fast and simple self-powered biosensor for cyanide detection based on the inhibitive effect was developed based on a CNTs/laccase biocathode on a microchip. ${ }^{[24 b]}$ Another example is related to a polyelectrolyte-GOx/CNTs bioanode via alayer-by-layer assembly, which showed a power density of $1.34 \mathrm{~mW} \mathrm{~cm}^{-2}$ when assembled into a glucose EBFC. ${ }^{[24 c]}$

Mano et al. demonstrated a high-power EBFC utilizing the newly engineered porous microwires comprised of assembled and oriented CNTs which overcome the limitations of 
small dimensions and large specific surface areas. ${ }^{[25]}$ Poor electron transfer and slow mass transport of substrates in the biosystem were greatly improved and subsequently the glucose $/ \mathrm{O}_{2}$ cell exhibited a maximum power density $\left(P_{\max }\right)$ of $740 \mu \mathrm{W} \mathrm{cm}{ }^{-2}$, as shown in Figure 1. This value is more than tenfold higher than the power density obtained for a carbon fiber EBFC. After $150 \mathrm{~h}$ of operation, the cell only lost $20 \%$ of its initial power density.

Cosnier et al. presented an efficient wiring of enzymes in a porous matrix of CNTs with a high electrical conductivity for the fabrication of glucose EBFCs via mechanical compression. ${ }^{[26]}$ CNT electrodes ensured a good diffusion for the enzyme substrate and the electrical connection of a large amount of entrapped enzymes. Moreover, the compression of the enzyme nanotube mixture likely favoured a close proximity at the nanoscale between nanotube and prosthetic sites of the enzymes, leading thus to DET without any loss of activity. The mediator-less EBFC delivered a high power density up to $1.3 \mathrm{~mW} \mathrm{~cm}^{-2}$ and an OCV of $0.95 \mathrm{~V}$. Moreover, it remained stable for 1 month and displayed $1 \mathrm{~mW} \mathrm{~cm}^{-2}$ power density under physiological conditions. Taking advantage of this improved performance, with respect to both power density and operational stability, the first EBFC implanted in an animal (i.e., a rat) was developed to generate electric energy from a mammal's body fluids and power electronic devices like a light-emitting diode (LED) or a digital thermometer (Figure 2). No signs of rejection or inflammation were observed after 110 days' implantation in the rat. Very recently, a one-year stability for a glucose $/ \mathrm{O}_{2}$ biofuel cell combined with $\mathrm{pH}$ reactivation of the compressed laccase/CNTs biocathode was demonstrated by the same group. ${ }^{\text {[26d] }}$

Another example is a membrane-free BFC based on a highly oriented and porous carbon nanotube yarn, which provided an OCV of $0.70 \mathrm{~V}$ and a $P_{\max }$ of $2.18 \mathrm{~mW} \mathrm{~cm}^{-2}{ }^{[27]}$ The BFC operation in human serum generated a high areal power output, as well as a markedly increased lifetime (83\% remained after $24 \mathrm{~h}$ ). Immobilizing the interconnected enzyme and the redox mediator in a highly conducting, porous electrode maximized their interaction with the electrolyte and minimized diffusion distances for fuel and oxidant, thereby enhancing the 
power density.

\subsection{Graphene}

The wealth of applications and dramatic improvements in the performance of EBFCs by CNTs has led researches on other carbon nanomaterials, such as graphene. Graphene possesses many functional properties that can be used to facilitate direct or mediated electrical contact between the redox site of the enzyme and electrode surfaces, and develop high-power EBFCs. ${ }^{[28]} \mathrm{Li}$ et al. designed a BFC consisting of co-immobilized graphene-GOx in a silica sol-gel matrix as the anode and graphene-BOD as the cathode. ${ }^{[29]}$ It exhibited a $P_{\max }$ of about $24.3 \mu \mathrm{W} \mathrm{cm}{ }^{-2}$, which is nearly two times larger than that of the CNT based BFC, with the performance of the graphene BFC lasting for 7 days. In another report, a nanographene platelet-based glucose/ $\mathrm{O}_{2} \mathrm{BFC}$ with glucose oxidase (GOD) as the anodic biocatalysts and the laccase as the cathodic biocatalysts was developed with a $P_{\max }$ of ca. $57.8 \mu \mathrm{W} \mathrm{cm}{ }^{-2}{ }^{[30]}$

Compared to its 2D configuration, the 3D assembly of graphene can create large accessible specific surface areas, interconnected conductive networks, and a special microenvironment. ${ }^{[31]}$ The endowed high porosity and diffusion characteristics enhanced the enzyme bioelectrocatalysis as well as improved the power density of EBFCs. ${ }^{[32]}$ A $3 \mathrm{D}$ graphene network synthesized with a $\mathrm{Ni}^{2+}$-exchange/KOH activation combination method were used as a substrate for the immobilization of laccase and mediator (Figure 3A). Due to the interconnected network structure and high surface area of the $3 \mathrm{D}$ graphene, the high catalytic activity for $\mathrm{O}_{2}$ reduction was facilitated. A glucose/ $\mathrm{O}_{2} \mathrm{BFC}$ combined with a $\mathrm{GOx}$ anode can output a $P_{\max }$ of $112 \mu \mathrm{W} \mathrm{cm}{ }^{-2}{ }^{[33]}$

Interestingly, there are contributions that combine other nano-objects like CNTs and metal nanoparticles (NPs) to construct 3D porous structures of graphene, further enhancing the enzymatic electrode kinetics and improving the power density of BFCs. Zhang and Zhu et al. reported graphene-Au NPs hybrids to support biocatalysts. ${ }^{[34]}$ The as-assembled BFCs reached a $P_{\max }$ of $1.96 \mathrm{~mW} \mathrm{~cm}{ }^{-2}$, which can light up red and yellow LEDs. And the EBFC 
retained $66 \%$ of the output after 70 days. With 3D Graphene/CNTs Cogel electrodes, a membrane/mediator-free rechargeable EBFC was reported. The enhanced power density are attributed to the high available surface area and porosity of the electrode material allowing for high loading of active enzymes and ease of glucose diffusion through the cogel-based electrode. ${ }^{[35]}$ In addition, 3D graphene was covered inside-out by a dense thin-film network of CNTs with a mesh size comparable to a macromolecule (Figure 3B). An glucose $/ \mathrm{O}_{2} \mathrm{BFC}$ equipped with enzyme-functionalized 3D graphene-CNT hybrid electrodes can nearly attain the theoretical limit of OCV $(\sim 1.2 \mathrm{~V})$ and the highest power density ever reported $(2.27 \pm$ $0.11 \mathrm{~mW} \mathrm{~cm}^{-2}$ ), with high stability. ${ }^{[36]}$

Up to now, graphene has been applied in EBFCs in a similar way as CNTs, without actually exploiting its full potential. Taking the advantages of potential merits of graphene, especially commercial benefits, high performance and low cost of the graphene-based EBFCs would be reachable goals.

\subsection{Porous Carbon Derived 3D Nanostructures}

Besides CNTs and graphene, other carbon materials such as carbon paper, carbon fiber, and carbon black can further be manipulated to form 3D porous structures that allow for high enzyme loading and connectivity with an ease of substrate diffusion into the network in the EBFC development. ${ }^{[37]}$ Porous carbon nanostructures with controlled porosity, high surface area and conductivity draw much attention in the application of EBFCs. The performance characteristics of recently developed porous carbon nanoarchitectures based EBFCs are described in the follow.

The Willner group introduced the use of mesoporous carbon NPs $(<500 \mathrm{~nm}$ in diameter, pore dimensions $\sim 6.3 \mathrm{~nm}$ ) as a functional material to electrically contact redox proteins with electrodes. ${ }^{[38]}$ The high surface area and the conducting properties of mesoporous carbon NPs are implemented to design electrically contacted enzyme electrodes for BFC applications. The mediators were trapped inside the pores by means of redox enzyme caps, resulting in 
integrated bioelectrocatalytic assemblies. Thus, a glucose $/ \mathrm{O}_{2}$ biofuel cell yields a power output of $\sim 95 \mu \mathrm{W} \mathrm{cm}{ }^{-2}$, as shown in Figure 4.

A hierarchically structured porous carbon electrode was prepared by the electrophoretic deposition (EPD) of magnesium oxide-templated mesoporous carbon (mean pore diameter of $38 \mathrm{~nm}) .{ }^{[39]}$ Based on macropores for efficient mass transport and mesopores for high enzyme loading, the resulting glucose bioanode obtained a current density for the oxidation of glucose of $100 \mathrm{~mA} \mathrm{~cm}{ }^{-2}$ at $25{ }^{\circ} \mathrm{C}$ and $\mathrm{pH}$ 7.This was 33 times higher than that on a flat carbon electrode at the same biocatalyst composition and loading. The efficient diffusion of the glucose is due to the relatively thin carbon layer $(<0.1 \mathrm{~mm})$ and its macroporous structure. Furthermore, the stability of the enzyme electrode was improved by using mesoporous carbon materials; after 220 days, more than $95 \%$ of the initial catalytic current remained.

Japanese researchers also demonstrated the stable generation of electricity of a glucosepowered mediated BFC based on porous carbon particles originating from rice husks through multiple refuelling cycles. ${ }^{[40]}$ The bioanode can be refuelled continuously for more than 60 cycles at $1.5 \mathrm{~mA} \mathrm{~cm}^{-2}$ without significant potential drop. The whole cells can be repeatedly used to power a portable music player at $1 \mathrm{~mW} \mathrm{~cm}^{-3}$ through 10 refuelling cycles. This refuelability is attributed to the immobilized electron-transfer mediator and redox enzymes in high concentrations on porous carbon particles maintaining their electrochemical and enzymatic activities.

Mano et al. showed that carbonaceous micro/macrocellular foams can be used for efficient and stable non-specific enzyme entrapment. ${ }^{[41]}$ 3D carbonaceous electrodes with interconnected hierarchical porosity were prepared using $\mathrm{Si}$ (HIPE) exotemplating matrices,and were modified with GOx and mediator (i.e., Os polymer). The glucose electrooxidation current was 13 -fold larger on the porous electrode than on glassy carbon for the same enzyme loading. When BOD was adsorbed into the porous electrode, the direct reduction of $\mathrm{O}_{2}$ to water provided a dramatic increase in enzyme loading which allowed for a 
500-fold current enhancement and stabilization of the DET current from few hours to several days as compared to conventional flat electrodes.

$\mathrm{Xu}$ and Armstrong used the compacted electrodes from graphitized mesoporous carbon nanopowder to provide a simple and inexpensive method for obtaining a large increase in productive enzyme loading, greatly increasing current densities and stability. ${ }^{[42]}$ Operated under non-explosive $\mathrm{H}_{2}$-rich air mixtures at $25^{\circ} \mathrm{C}$, typical power density from a $\mathrm{H}_{2} / \mathrm{O}_{2} \mathrm{BFC}$ at a stationary hydrogenase anode and a BOD cathode exceeded $1 \mathrm{~mW} \mathrm{~cm}^{-3}$. Good prospects for stability were demonstrated by the fact that $90 \%$ of the power was retained after continuously working for $24 \mathrm{~h}$, and more than half of the power was retained after one week of non-stop operation. The 3D porous electrodes worked by greatly increasing the catalysts loading (at both the anode and the cathode) and selectively restricting the access of $\mathrm{O}_{2}$ (relative to $\mathrm{H}_{2}$ ) to enzymes embedded in pores at the anode.

\section{Porous Noble Metal Nanoarchitectures for EBFCs}

Porous noble metal (such as $\mathrm{Au}, \mathrm{Ag}, \mathrm{Pt}, \mathrm{Pd}$ ) nanostructures featuring large specific surface areas, high porosity, intrinsic conductivity, and biocompatibility can yield rapid electron and mass transport pathways for bioelectrocatalysis. ${ }^{[43]}$ Enzymes conjugated with the nanostructured metal surface in-/outside the pores retain their natural conformation and hence the activity due to the comparable dimensions. In this respect, they found significant interest for EBFC applications, as they are likely to improve the key issues of lifetime and power density. Even though there are some results on the utilization of nanoporous $\mathrm{Au}^{[44]}$, significant results were achieved with 3D porous metal nanomaterials in a bottom-up approach of noble metal NPs. In the following, some of the attractive features of porous noble metal nanoarchitectures from NPs assembly and NPs supported on porous templates are discussed.

\subsection{Porous Structures from Metal NPs}

The use of noble metal NPs as bulding blocks for 3D porous architectures can be considered as an attractive option for an enzyme loading matrix and current collector in EBFCs. For 
example, Willner et al. developed 3D bioelectrodes via electropolymerization of biocatalysts and metal NPs, where both enzyme and particles were modified with electropolymerizable units, namely thioaniline. ${ }^{[45]}$ The biocathode consisting of a composite of BOD and Pt NPs revealed an effective electrocatalyzed reduction of $\mathrm{O}_{2}$. GDH and Au NPs were assembled on a roughened Au electrode for the bioelectrocatalyzed oxidation of glucose with a high turnover rate of electrons of ca. $\mathrm{k}_{\mathrm{et}}=1100$ electrons $\mathrm{s}^{-1}$. The accelerated bioelectrocatalysis reduction and oxidation together with the power output were driven by the $3 \mathrm{D}$ conductive hybrid enzyme/NPs network. In addition, electrostatic layer-by-layer assemblies of metal NPs and enzymes have been applied in bioelectrodes for EBFC construction. ${ }^{[43 a, 46]}$

As a new emerging porous metal nanomaterial for bioelectrocatalysis, noble metal aerogels derived from NPs via controlled destabilization exhibit high surface areas, through-connected porosity distributed from the micro- to the macro- pore size range, and retained metrics of the NPs (Figure 6). ${ }^{[47]}$ The Eychmüller group reported a controllable synthesis of Pd aerogels with high surface area and porosity by destabilizing colloidal solutions of Pd NPs with variable concentrations of calcium ions. Compared to glassy carbon and Pd NPs, enzyme electrodes based on Pd aerogels co-immobilized with GOD showed much faster electrontransfer kinetics of the mediator and mass transport of the mediator at the electrode surface. $^{[47 b]}$ Then, a Pd aerogel-based BFC was developed, in which the ferrocene $(\mathrm{Fc})$ coupled Pd aerogel not only provided a 3D porous support for the biocatalyst, but also mediated the bioelectrocatalytic oxidation of glucose as an integrated bioanode. BOD encapsulated into a $\mathrm{Pd}-\mathrm{Pt}$ alloy aerogel realized the direct electrocatalytic reduction of $\mathrm{O}_{2}$ at the biocathode. ${ }^{[47 c]}$ Further attempts to enhance the power output of the BFC by improving the GOx anode performance through the use of mediators with low redox potential areunderway.

\subsection{Porous Template Assisted Metal NPs Nanoarchitectures}

Bottom-up approaches based on the use of porous templates such as carbon, metal, metal oxide, polymer, and even bacteria, are advantageously exploited for porous noble metal 
nanoartitectures in the EBFC development. A DET-based laccase biocathode for $\mathrm{O}_{2}$ electroreduction at low overpotentials was demonstrated via a step-by-step covalent attachment of Au NPs to porous graphite electrodes, as shown in Figure 7A. The oriented immobilized laccase molecules that were efficiently wired by the Au NPs showed a very fast DET with a heterogeneous electron transfer rate constant $\mathrm{k}_{0} \gg 400 \mathrm{~s}^{-1} \cdot{ }^{[48]} 3 \mathrm{D}$ nanostructured microscale $\mathrm{Au}$ electrodes with an electrochemically driven transformation of physically deposited Au NPs modified with suitable biocatalysts are the work of the same group. ${ }^{[49]} \mathrm{A}$ mediator-, cofactor-, and membrane-less BFC operated in cerebrospinal fluid and in the brain of a rat, producing amounts of electrical power sufficient to drive a self-contained biodevice. It is also capable of generating electrical energy from human lachrymal liquid by utilizing the ascorbate and $\mathrm{O}_{2}$ naturally present in tears as fuel and oxidant, with a stable current density output of over $0.55 \mu \mathrm{A} \mathrm{cm}^{-2}$ at $0.4 \mathrm{~V}$ for $6 \mathrm{~h}$ of continuous operation.

A high power and stable membrane-less, mediator-free glucose BFC with ultrathin configuration was achieved using a Ag NP-functionalized hierarchical mesoporous titania thin film electrodes, where GOx and laccase were immobilized and served as anodic and cathodic catalyst, respectively. The mesoporous silica film facilitated mass transport of products and reactants to/from the electrodes while the Ag NPs enhanced the electrical connection between the biocatalyst and the thin layer electrode. A $P_{\max }$ of $602 \mu \mathrm{W} \mathrm{cm}{ }^{-2}$ at $0.68 \mathrm{~V}$ was delivered; only about $10 \%$ loss in voltage output was observed after continuous operation for $30 \mathrm{~h} \cdot{ }^{[50]} \mathrm{In}$ addition, with cellulose templated Au and Pt NPs, a 3D origami-based BFC was demonstrated for self-powered, low-cost, and sensitive biosensing. ${ }^{[51]}$ Another interesting example is the design of a bioanode consisting of GOx covalently attached to Au NPs that are assembled onto a genetically engineered M13 bacteriophage, a high-surface area template. The resulting “nanomesh" architecture exhibited DET and achieved a higher current density of $1.2 \mathrm{~mA} \mathrm{~cm}{ }^{-2}$ towards glucose oxidation, compared to most other DET attachment schemes. ${ }^{[52]}$

\section{Polymeric Nanostructured Matrix for EBFCs}


Porous nanostructures from polymeric materials have also attracted attention in BFC investigations. Nafion, biopolymers (chitosan, poly(lactic acid), etc.), conducting polymers (polyaniline, polypyrrole, poly(3,4-ethylenedioxythiophene), etc.), and composite polymers have widely been used in EBFCs. ${ }^{[53]}$ Rather than the functionalities of redox mediators or ionselective membranes, we here mainly focus on their utilization for the construction of bioelectrodes in EBFCs.

The biocompatible polymer-based 3D electrodes exhibiting multidimensional and multidirectional pore structures, which are abundant, biodegradable and cost-effective, are possible solutions to improve the performance of EBFCs for further biological application. One of the important examples is chitosan scaffold, which was used to fabricate enzymatic electrode that oxidized glucose and produced electrical current more effectively than the same electrode made of a chitosan film. ${ }^{[54]}$ In addition, the rapid oxidation of dopamine or 1noradrenaline by $\mathrm{K}_{3} \mathrm{Fe}(\mathrm{CN})_{6}$ yields a catecholamine polymer with GOx effectively entrapped. Such an enzyme-entrapped polydopamine was applied as a bioanode for BFC which showed a $P_{\max }$ of $1.62 \mathrm{~mW} \mathrm{~cm}^{-2} \cdot{ }^{[55]}$ Conducting polymers with high electrical conductivity and excellent inherent environmental stability have been used as immobilization matrix for enzymes and mediator compounds. ${ }^{[56]}$ For instance, GOx immobilized in the porous matrix of polyaniline nanofibers showed high activity and stablity. Combining an air-breathing biocathode, the BFCs delivered a $P_{\max }$ of $292 \mu \mathrm{W} \mathrm{cm}{ }^{-2}$, respectively. ${ }^{[57]}$

Recently, the integration of nanosized conductive components, such as metal and carbon, increase the conductivity of the polymers for the facility of electron transfer in EBFCs, as displayed in Figure 8. ${ }^{[58]}$ L-DOPA was chemically and electrochemically synthesized and used as an in situ enzyme-immobilization matrix for the BFC application. A GOx-bioanode was prepared through chemical oxidative polymerization of L-DOPA by Au precursors in the presence of GOx. The enzyme electrode based on this polymer-NP hybrid matrix showed an OCP of ca. $1.0 \mathrm{~V}$ and a high $P_{\max }$ of $2.62 \mathrm{~mW} \mathrm{~cm}^{-2}$, when assembled into a glucose/ $\mathrm{O}_{2}$ 
BFC. ${ }^{[58 b]}$ The incorporation of chitosan into CNTs achieved a significant increase in longevity and stability of laccase-based biocathodes, namely a stable current response during 2 months. The absence of enzyme inhibition (in $\mathrm{Cl}^{-}$or neutral $\mathrm{pH}$ ) over time could be attributed to the protection of the enzyme by the microenvironment created by the porous 3D-polymer matrix which also prevented the enzyme release in the solution and provided good $\mathrm{O}_{2}$ diffusion. ${ }^{[58 c]}$

\section{Conclusion and Perspectives}

It can be concluded that the introduction of porous nanostructures in EBFCs enabled the development of highly active and stable enzyme bioelectrodes, and thus improved the performance of the cells. With the use of novel characteristics like high surface area, open porosity, and nanoscale effect, porous nanostructured materials with good conductivity have several benefits. They play an important role as immobilization matrix, one of the key issues in the EBFC development: (1) increasing the enzyme loading with respect to the amount and efficiency due to the extremely high surface area and comparable dimensions from both the size of nanomaterials and the pore size; (2) providing preferred orientation of immobilized enzymes for DET; (3) immobilizing redox mediators, if needed, without leakage for MET. Secondly, the roughness and dimensionality of porous nanostructures maximize the availability of electron transfer, allowing to decrease the distance between the active sites and the electrode conductor to improve electron transfer and therefore increase the currents for both DET and MET. Very importantly, the high porosity with the pores being large facilitates the mass transport in the EBFC system in terms of the permeation of electrolyte, fuels, and oxidant. Finally, because of the pore structure and the nano-dimensions, they can improve the stability in two main ways: (1) they can prevent leaching of the biomolecule into solution to increase the re-usability of the bioelectrodes and (2) they can provide a better microenvironment for the biomolecule that helps in retaining its structure and function. 
Up to now, significant progress has been achieved in EBFCs based on porous nanostructured materials. The power density increased from $\mu \mathrm{W} \mathrm{cm}-2$ to $\mathrm{mW} \mathrm{cm}$ and the stability extended from hours to about one year. But still such parameters are too low for a performance in commercial applications. The DET would be advantageous to increase the cell OCV and simplify the setup. However, most of the biocatalysts (i.e., GOx) keep their active sites deep in protein shells, which obstruct the direct bioelectrocatalysis of fuels and oxidants. There are some successful examples based on DET, yet they generally yield low current densities. MET with higher bioelectrocatalytic current is limited by the decreased lifetime due to the instability of cycling redox mediators. To make further progress, the combined efforts from materials scientist and biologist are highly desirable. On the one hand, it is critical to develop new designs of materials to improve the bioelectrocatalytic interface and stabilize the biocatalysts, and to optimize the pore structures to overcome the block of the mass transport. On the other hand, protein engineering makes the DET with high current density impossible and the utilization of enzyme cascades dramatically improve the oxidation efficiency of the fuels. In this respect, further research on improving the electrochemical performance and stability along these lines are still needed.

\section{Acknowledgements}

This work is supported by the AEROCAT project (ERC-2013-ADG 340419) and the DFG project EY16/10-2. D. W. acknowledges the support from the Alexander von Humboldt Foundation.

Received: ((will be filled in by the editorial staff))

Revised: ((will be filled in by the editorial staff)) Published online: ((will be filled in by the editorial staff))

[1] a) F. Davis, S. P. J. Higson, Biosens. Bioelectron. 2007, 22, 1224; b) F. Zhao, R. C. T. Slade, J. R. Varcoe, Chem. Soc. Rev. 2009, 38, 1926.

[2] R. A. Bullen, T. C. Arnot, J. B. Lakeman, F. C. Walsh, Biosens. Bioelectron. 2006, 21, 2015. 
[3] a) S. C. Barton, J. Gallaway, P. Atanassov, Chem. Rev. 2004, 104, 4867; b) D. Leech, P. Kavanagh, W. Schuhmann, Electrochim. Acta 2012, 84, 223; c) J. Yang, S. Ghobadian, P. J. Goodrich, R. Montazami, N. Hashemi, Phys. Chem. Chem. Phys. 2013, 15, 14147.

[4] A. T. Yahiro, S. M. Lee, D. O. Kimble, Biochim. Biophys. Acta 1964, 88, 375.

[5] a) A. Heller, Phys. Chem. Chem. Phys. 2004, 6, 209; b) M. Zhou, S. Dong, Acc. Chem. Res. 2011, 44, 1232; c) M. Falk, C. W. Narváez Villarrubia, S. Babanova, P. Atanassov, S. Shleev, ChemPhysChem. 2013, 22, 2045.

[6] E. Katz, A. F. Bückmann, I. Willner, J. Am. Chem. Soc. 2001, 123, 10752.

[7] N. Mano, F. Mao, A. Heller, J. Am. Chem. Soc. 2003, 125, 6588.

[8] H. Sakai, T. Nakagawa, Y. Tokita, T. Hatazawa, T. Ikeda, S. Tsujimura, K. Kano, Energy Environ. Sci. 2009, 2, 133.

[9] a) J. Kim, H. Jia, P. Wang, Biotechnol. Adv. 2006, 24, 296; b) M. J. Moehlenbrock, S. D. Minteer, Chem. Soc. Rev. 2008, 37, 1188; c) c) R. A. S. Luz, A. R. Pereira, J. C. P. Souza, F. C. P. F. Sales, F. N. Crespilho, Chemelectrochem 2014, 1, 1751.

[10] a) S. D. Minteer, Top Catal. 2012, 55, 1157; b) K. Min, Y. J. Yoo, Biotechnol. Bioprocess Eng. 2014, 19, 553.

[11] a) M. J. Cooney, V. Svoboda, C. Lau, G. Martin, S. D. Minteer, Energy Environ. Sci. 2008, 1, 320; b) J. Kim, J. W. Grate, P. Wang, Chem. Eng. Sci. 2006, 61, 1017; c) A. Walcarius, S. D. Minteer, J. Wang, Y. Lin, A. Merkoçi, J. Mater. Chem. B 2013, 1, 4878.

[12] a) J. Kim, J. W. Grate, Nano Lett. 2003, 3, 1219; b) M. B. Fischback, J. K. Youn, X. Y. Zhao, P. Wang, H. G. Park, H. N. Chang, J. Kim, S. Ha, Electroanalysis 2008, 18, 2016.

[13] a) A. Walcarius, Chem. Soc. Rev. 2013, 42, 4098. b) H. W. Liang, X. Cao, F. Zhou, C. H. Cui, W. J. Zhang, S. H. Yu, Adv. Mater. 2011, 23, 1467.

[14] a) S. Sattayasamitsathit, A. M. O’Mahony, X. Y. Xiao, S. M. Brozik, C. M. Washburn, D. R. Wheeler, W. Gao, S. D. Minteer, J. Cha, D. B. Burckel, R. Polsky, J. Wang, J. Mater. Chem. 2012, 22, 11950; b) P. N. Catalano, A. Wolosiuk, G. J. A. A. Soler-Illi, M. G. Bellinoa, 
Bioelectrochemistry 2015, 106, 14; c) T. Q. N. Do, M. Varničić, R. J. Flassig, T. VidakovićKoch, K. Sundmacher, Bioelectrochemistry 2015, 106, 3.

[15] a) M. N. Nasharudin, S. K. Kamarudin, U. A. Hasran, M. S. Masdar, Inter. J. Hydrogen Energy 2014, 39, 1039; b) X. F. Chen, D. Cui, X. J. Wang, X. H. Wang, W. S. Li, Biosens. Bioelectron. 2015, 69, 135.

[16] a) Z. Zhou, M. Hartmann, Top Catal. 2012, 55, 1081; b) S. Nardecchia, D. Carriazo, M. L. Ferrer, M. C. Gutiérrez, F. Monte, Chem. Soc. Rev. 2013, 42, 794; c) T. Tamaki, Top Catal. 2012, 55, 1162.

[17] S. Iijima, Nature 1991, 354, 56.

[18] a) W. Feng, P. Ji, Biotechnol. Adv. 2011, 29, 889; b) A. A. Babadi, S. Bagheri, S. B. Hamid, Biosens Bioelectron. 2016, 15, 850.

[19] Y. Liu, M. Wang, F. Zhao, B. Liu, S. Dong, Chem. Eur. J. 2005, 11, 4970.

[20] Y. Yan, W. Zheng, L. Su, L. Mao, Adv. Mater. 2006, 18, 2639.

[21] a) Y. Yan, L. Su, L. Mao, J. Nanosci. Nanotechnol. 2007, 7, 1625; b) Y. Liu, S. Dong, Biosens. Bioelectron. 2007, 23, 593; c) S. D. Minteer, P. Atanassov, H. R. Luckarift, G. R. Johnson, Materials Today 2012, 15, 156; d) S. Cosnier, M. Holzinger, A. L. Goff, Front Bioeng Biotechnol. 2014, 2, 45.

[22] a) D. Wen, X. Xu, S. Dong, Energy Environ. Sci. 2011, 4, 1358; b) D. Wen, L. Deng, S. Guo, S. Dong, Anal. Chem. 2011, 83, 3968.

[23] a) M. Inagaki, K. Kaneko, T. Nishizawa, Carbon 2004, 42, 1401; b) K. Murata, K. Kaneko, F. Kokai, K. Takahashi, M. Yudasaka, S. Iijima, Chem. Phys. Lett. 2000, 331, 14.

[24] a) L. Deng, L. Shang, Y. Wang, T. Wang, H. Chen, S. Dong, Electrochem. Commun. 2008, 10, 1012; b) L. Deng, C. Chen, M. Zhou, S. Guo, E. Wang, S. Dong, Anal. Chem. 2010, 82, 4283; c) K. H. Hyun, S. W. Han, W.-G. Koh, Y. Kwon, J. Power Sources 2015, 286, 197.

[25] F. Gao, L. Viry, M. Maugey, P. Poulin, N. Mano. Nat. Commun. 2010, 1, 2.

[26] a) A. Zebda, C. Gondran, A. L. Goff, M. Holzinger, P. Cinquin, S. Cosnier, Nat. Commun. 
2011, 2, 370; b) A. Zebda, S. Cosnier, J.-P. Alcaraz, M. Holzinger, A. L. Goff, C. Gondran, F. Boucher, F. Giroud, K. Gorgy, H. Lamraoui, P. Cinquin, Sci. Rep. 2013, 3, 1516; c) B. Reuillard, A. L. Goff, C. Agnes, M. Holzinger, A. Zebda, C. Gondran, K. Elouarzaki, S. Cosnier, Phys. Chem. Chem. Phys. 2013, 15, 4892; d) B. Reuillard, C. Abreu, N. Lalaoui, A. L. Goff, M. Holzinger, O. Ondel, F. Buret, S. Cosnier, Bioelectrochemistry 2015, 106, 73.

[27] C. H. Kwon, S.-H. Lee1, Y.-B. Choi, J. A. Lee, S. H. Kim, H.-H. Kim, G. M. Spinks, G. G. Wallace, M. D. Lima, M. E. Kozlov, R. H. Baughman, S. J. Kim. Nat. Commun. |2014, 5, 3928.

[28] a) Y. Ravenna, L. Xia, J. Gun, A. A. Mikhaylov, A. G. Medvedev, O. Lev, L. Alfonta, Anal. Chem. 2015, 87, 9567; b) J. Filip, J. Tkac, Electrochimica Acta 2014, 136, 340; c) A. Karimi, A. Othman, Aytekin. Uzunoglu, L. Stanciu, S. Andreescu, Nanoscale 2015, 7, 6909.

[29] C. Liu, S. Alwarappan, Z. Chen, X. Kong, C.-Z. Li, Biosens. Bioelectron. 2010, 25, 1829.

[30] W. Zheng, H. Y. Zhao, J. X. Zhang, H. M. Zhou, X. X. Xu, Y. F. Zheng, Y. B. Wang, Y. Cheng, B. Z. Jang, Electrochem. Commun. 2010, 12, 869.

[31] a) Z. Chen, W. Ren, L. Gao, B. Liu, S. Pei, H.-M. Cheng, Nat. Mater. 2011, 10, 424; b) Z. Niu, J. Chen, H. H. Hng, J. Ma, X. A. Chen, Adv. Mater. 2012, 24, 4144.

[32] a) H. Gao, H. Duan, Biosens. Bioelectron. 2014, 65, 404; b) Y. Song, C. Chen, C. Wang, Nanoscale 2015, 7, 7084; c) L. Qian, L. Lu, $R S C A d v$. 2014, 4, 38273; d) M. M. Jaafar, G. P. M. K. Ciniciato, S. A. Ibrahim, S. M. Phang, K. Yunus, A. C. Fisher, M. Iwamoto, P. Vengadesh, Langmuir 2015, 31, 10426.

[33] Y. Zhang, M. Chu, L. Yang, Y. Tan, W. Deng, M. Ma, X. Su, Q. Xie, ACS Appl. Mater. Interfaces 2014, 6, 12808.

[34] a) P. Gai, Y. Ji, Y. Chen, C. Zhu, J. Zhang, J. J. Zhu Analyst 2015, 140, 1822; b) Y. Chen, P. Gai, J. Zhang, J. J. Zhu, J. Mater. Chem. A 2015, 3, 11511; c) P. Gai, Y.-S. Jia, W. J. Wang, R. B. Song, C. Zhu, Y. Chen, J. Zhang, J. J. Zhu, Nano Energy 2016, 19, 541.

[35] A. S. Campbell, Y. J. Jeong, S. M. Geier, R. R. Koepsel, A. J. Russell, M. F. Islam, ACS 
Appl. Mater. Interfaces 2015, 7, 4056.

[36] K. P. Prasad, Y. Chen, P. Chen, ACS Appl. Mater. Interfaces 2014, 6, 3387.

[37] a) S. C. Barton, Y. Sun, B. Chandra, S. White, J. Hone, Electrochem. Solid State Lett. 2007, 10, 96; b) S. Tsujimura, M. Kawaharada, T. Nakagawa, K. Kano, T. Ikeda Electrochem. Commun. 2003, 5, 138; c) T. Tamaki, T, Yamaguchi, Ind. Eng. Chem. Res. 2006, 45, 3050; d) T. Tamaki, Top Catal 2012, 55, 1162; d) I. Shitanda, S. Kato, Y. Hoshi, M. Itagakia, S. Tsujimura, Chem. Commun. 2013, 49, 11110.

[38] a) A. Trifonov, K. Herkendell, R. Tel-Vered, O. Yehezkeli, M. Woerner, I. Willner, ACS Nano, 2013, 7, 11358; b) A. Trifonov, R. Tel-Vered, M. Fadeev, I. Willner, Adv. Energy Mater. 2015, 5, 1401853.

[39] S. Tsujimura, K. Murata, W. Akatsuka, J. Am. Chem. Soc. 2014, 136, 14432.

[40] S. Fujita, S. Yamanoi, K. Murata, H. Mita, T. Samukawa, T. Nakagawa, H. Sakai, Y. Tokita, Sci. Rep. 2014, 4, 4937.

[41] a) V. Flexer, N. Brun, R. Backov, N. Mano, Energy Environ. Sci. 2010, 3, 1302; b) V. Flexer, N. Brun, O. Courjean, R. Backov, N. Mano, Energy Environ. Sci. 2011, 4, 2097.

[42] L. Xu, F. A. Armstrong, Energy Environ. Sci. 2013, 6, 2166; L. Xu, F. A. Armstrong, RSC Adv. 2015, 5, 3649.

[43] a) L. Deng, F. Wang, H. Chen, L. Shang, L. Wang, T. Wang, S. Dong, Biosens. Bioelectron. 2008, 24, 329; b) C. Zhu, D. Du, A. Eychmüller, Y. Lin, Chem. Rev. 2015, 115, 8896; c) L. Y. Chen, T. Fujita, M. W. Chen, Electrochim. Acta 2012, 67, 1.

[44] a) M. Hakamada, M. Takahashi, M. Mabuchi, Gold Bull 2012, 45, 9; b) U. Salaj-Kosla, M. D. Scanlon, T. Baumeister, K. Zahma, R. Ludwig, P. Ó. Conghaile, D. MacAodha, D. Leech, E. Magner, Anal. Bioanal. Chem. 2013, 405, 3823; c) C. T. Hou, D. P. Yang, B. Liang, A. H. Liu, Anal. Chem. 2014, 86, 6057; d) H. du Toit, M. D. Lorenzo, Biosens. Bioelectron. 2015, 69, 199.

[45] a) Y. M. Yan, I. Baravik, R. Tel-Vered, I. Willner, Adv. Mater. 2009, 21, 4275; b) O. 
Yehezkeli, R. Tel-Vered, S. Raichlin, I. Willner, ACS Nano 2011, 5, 2385.

[46] A. Lesniewski, M. Paszewski, M. Opallo, Electrochem Commun 2010, 12, 435.

[47] W. Liu, A.-K. Herrmann, N. C. Bigall, P. Rodriguez, D. Wen, M. Oezaslan, T. J. Schmidt, N. Gaponik, A. Eychmüller, Acc. Chem. Res. 2015, 48, 154; b) D. Wen, A.-K. Herrmann, L. Borchardt, F. Simon, W. Liu, S. Kaskel, A. Eychmüller, J. Am. Chem. Soc. 2014, 136, 2727; c) D. Wen, W. Liu, A.-K. Herrmann, A. Eychmüller, Chem. Eur. J. 2014, 20, 4380.

[48] C. Gutiérrez-Sánchez, M. Pita, C. Vaz-Domínguez, S. Shleev, A. L. De Lacey, J. Am. Chem. Soc. 2012, 134, 17212.

[49] V. Andoralov, M. Falk1, D. B. Suyatin, M. Granmo, J. Sotres, R. Ludwig, V. O. Popov, J. Schouenborg, Z. Blum, S. Shleev, Sci. Rep. 2013, 3, 3270; b) M. Falk, V. Andoralov, M. Silow, M. D. Toscano, S. Shleev, Anal. Chem. 2013, 85, 6342.

[50] M. G. Bellino, G. J. A. A. Soler-Illia, Small 2014, 10, 2834.

[51] a) Y. Wang, L. Ge, P. Wang, M. Yan, J. Yu, S. Ge, Chem. Commun. 2014, 50, 1947; b) Y. Wang, L. Ge, C. Ma, Q. Kong, M. Yan, S. Ge, J. Yu, Chem. Eur. J. 2014, 20, 12453.

[52] R. A. Blaik, E. Lan, Y. Huang, B. Dunn, ACS Nano 2016, 10, 324.

[53] H. Vaghari, H. Jafarizadeh-Malmiri, A. Berenjian, N. Anarjan, Sustain. Chem. Process. 2013, 1, 16; b) X. Y. Yang, G. Tian, N. Jiang, B. L. Su, Energy Environ. Sci. 2012, 5, 5540; c) J. Filip, R. Monosik, J. Tkac, Int. J. Electrochem. Sci. 2014, 9, 2491.

[54] M. J. Cooney, C. Lau, M. Windmeisser, B. Y. Liaw, T. L. Klotzbach, S. D. Minteer, J. Mater. Chem. 2008, 18, 667; b) C. Lau, G. Martin, S. D. Minteer, M. J. Cooney, Electroanalysis 2010, 22, 793.

[55] C. Chen, L. H. Wang, Y. M. Tan, C. Qin, F. Y. Xie, Y. C. Fu, Q. J. Xie, J. H. Chen, S. H. Yao, Biosens. Bioelectron. 2011, 26, 2311.

[56] X. J. Wang, P. Sjöberg-Eerola, K. Immonen, J. Bobacka, M. Bergelin, J. Power Sources 2011, 196, 4957; b) R.-M. Latonen, X. J. Wang, P. Sjöberg-Eerola, J. -E. Eriksson, M. Bergelin, J. Bobacka, Electrochim. Acta 2012, 68, 25. 
[57] H. Kim, I. Lee, Y. Kwon, B. C. Kim, S. Ha, J. -H. Lee, J. Kim, Biosens. Bioelectron. 2011, 26, 3908.

[58] a) C. Liu, Z. Chen, C. Z. Li, IEEE Trans. Nanotechnol. 2011, 10, 59; b) M. Z. Dai, L. G. Sun, L. Chao, Y. M. Tan, Y. C. Fu, C. Chen, Q. J. Xie, ACS Appl. Mater. Interfaces 2015, 7, 10843; c) S. E. Ichi, A. Zebda, A. Laaroussi, N. Reverdy-Bruas, D. Chaussy, M. N. Belgacem, P.Cinquina, D. K. Martin, Chem. Commun. 2014, 50, 14535. 


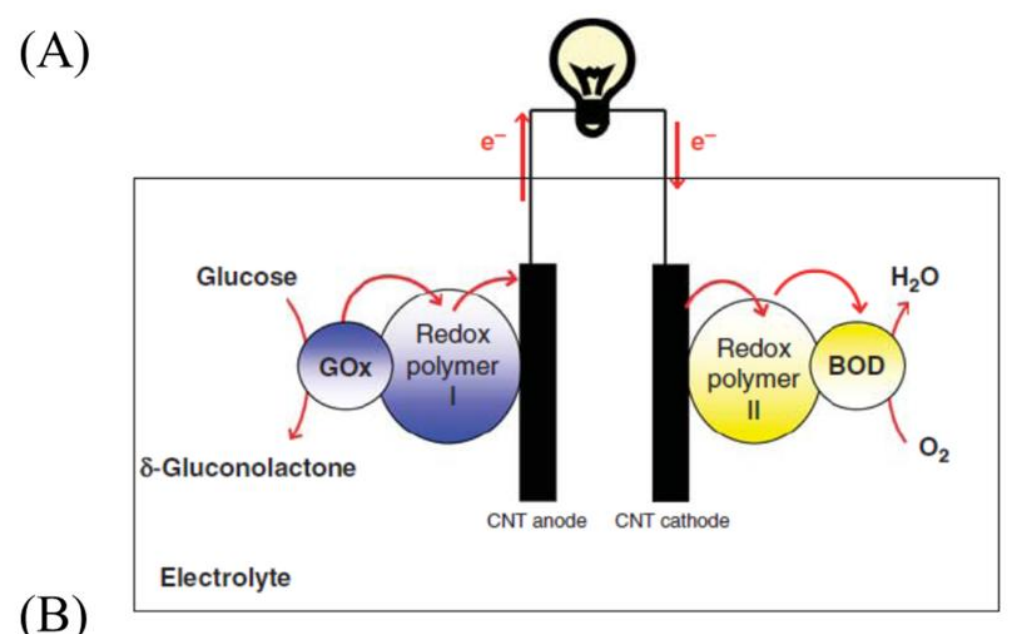

(B)
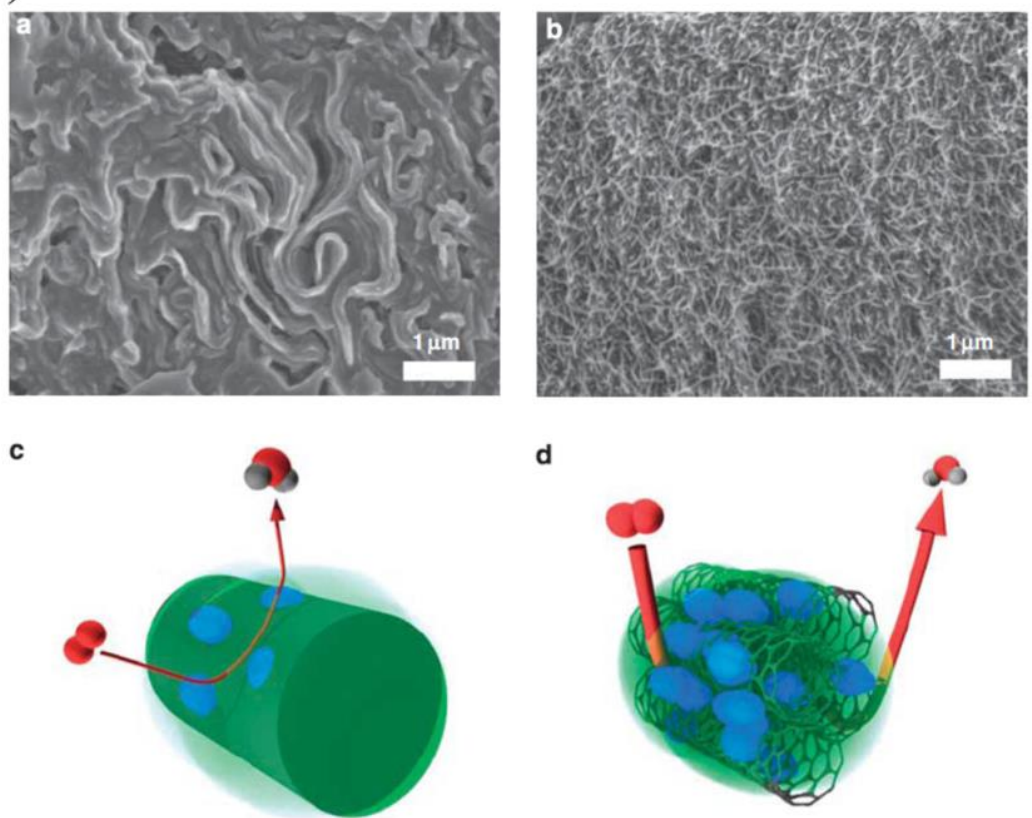

d

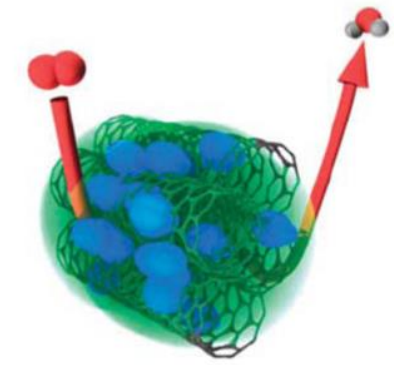

Figure 1. (A) Scheme of the BFC based on CNT fibres. (B) Scanning electron images of a carbon fibre (a) and a CNT fibre (b), and oxygen reduction on the modified carbon fibre (c) and CNT fibre (d). Reproduced from Ref. 25. 

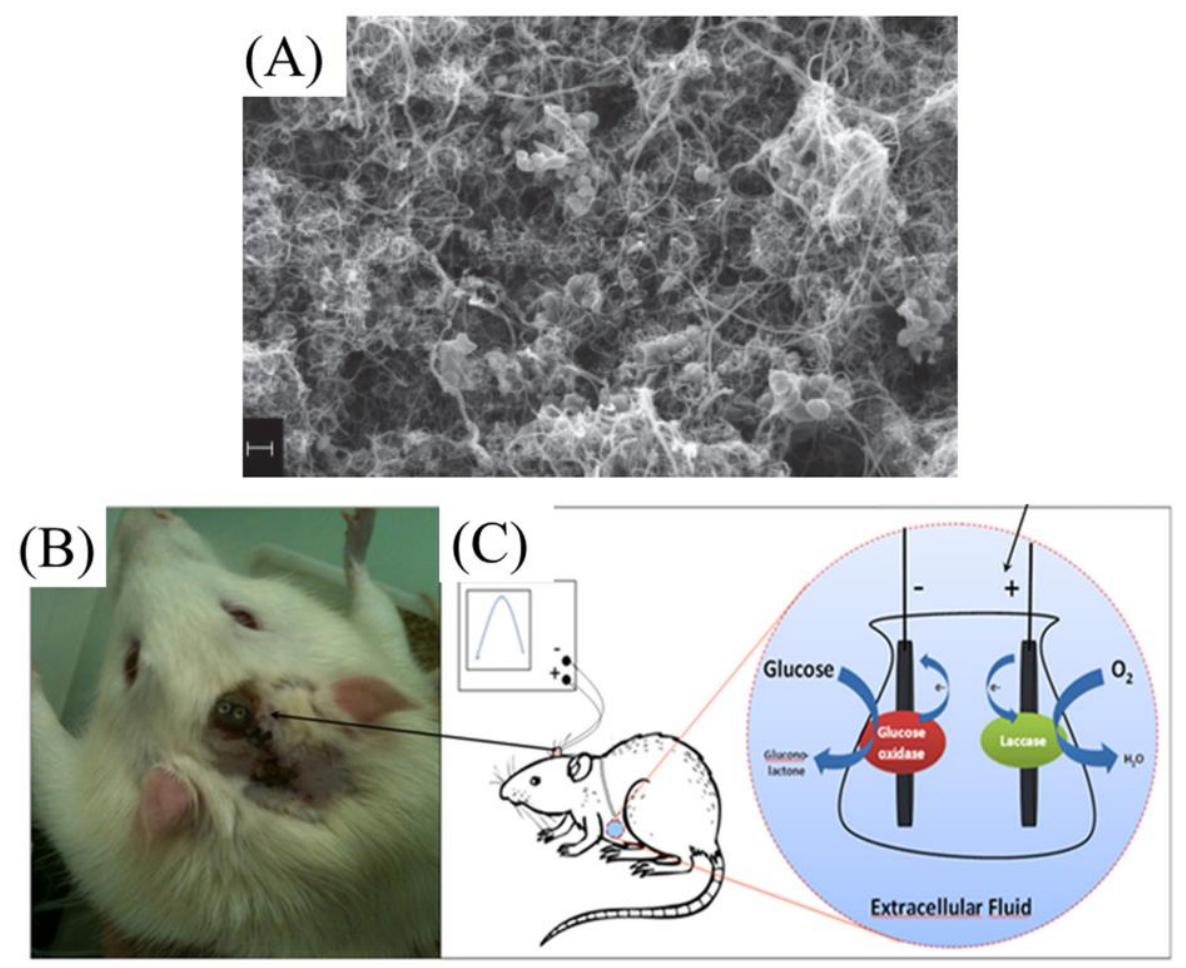

Figure 2. (A) SEM micrograph of a cross-section of the bioanode. The scale bar corresponds to $200 \mathrm{~nm}$. (B, C) Schematic representation from bioelectrodes to a biocompatible BFC which implanted in the abdominal cavity of a rat. Reproduced from Ref. $26 \mathrm{~b}$.

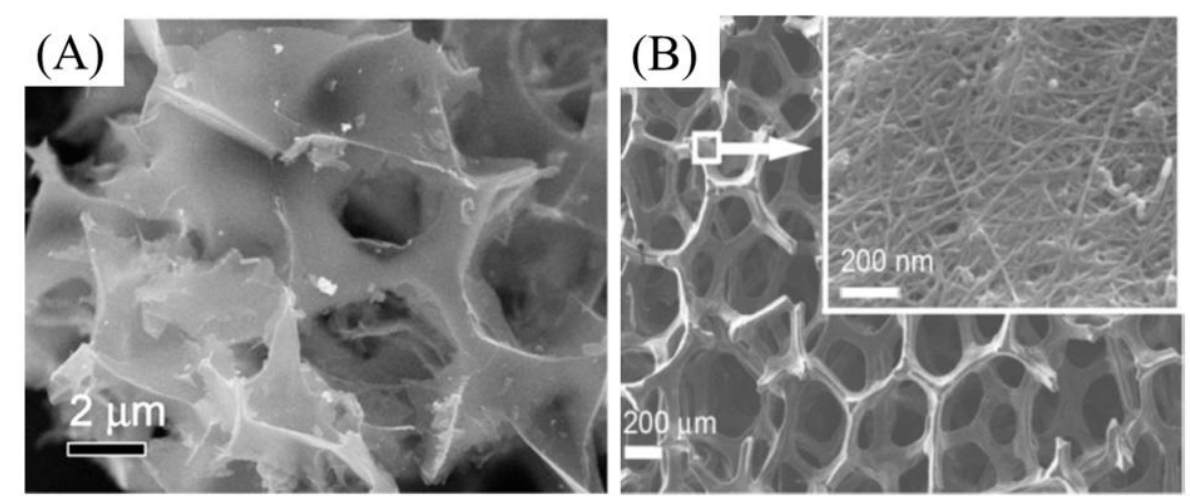

Figure 3. SEM images of 3D-graphene (A) and 3D graphene-SWCNT hybrids (B). Reproduced from Ref. 33 and 36. 


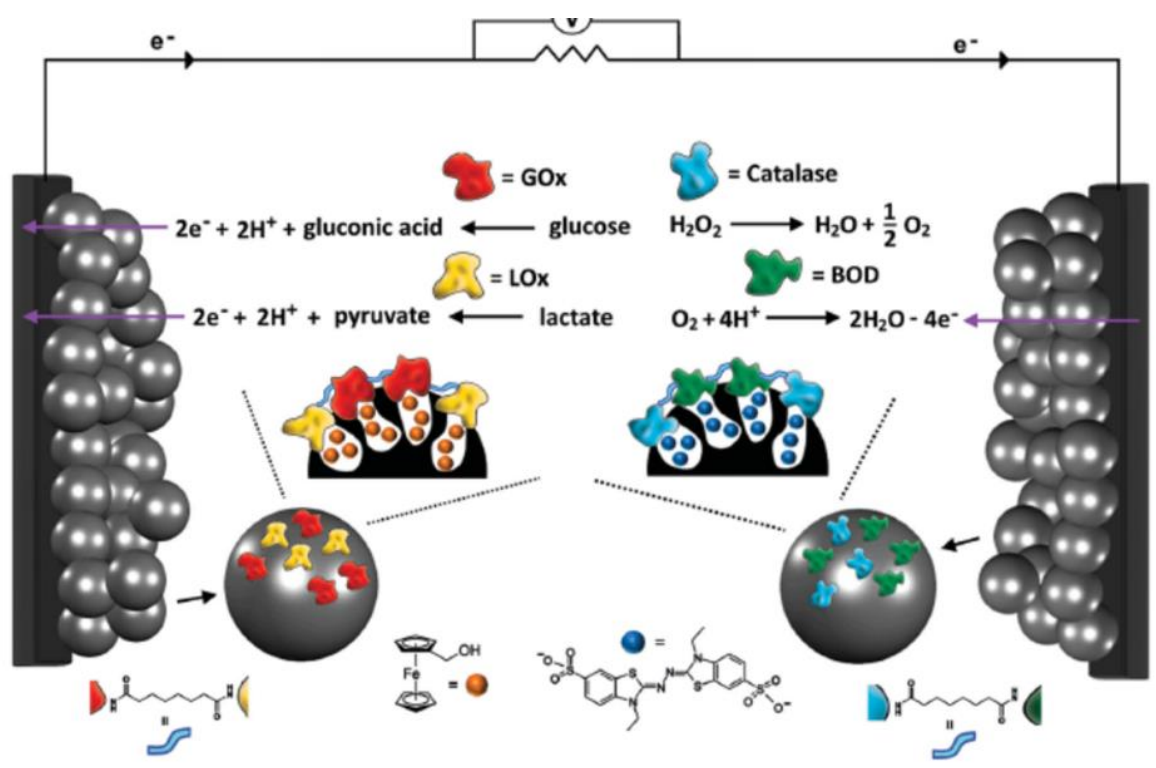

Figure 4. Schematic configuration of a BFC composed of a GOx/LOx capped mesoporous carbon NP-modified anode, oxidizing both the glucose and the lactate fuels, and BOD/Catalase-capped MPC NP-mesoporous carbon NPs-modified cathode that utilizes $\mathrm{O}_{2}$ and $\mathrm{H}_{2} \mathrm{O}_{2}$ as oxidizers. Reprinted from Ref. 38b. 

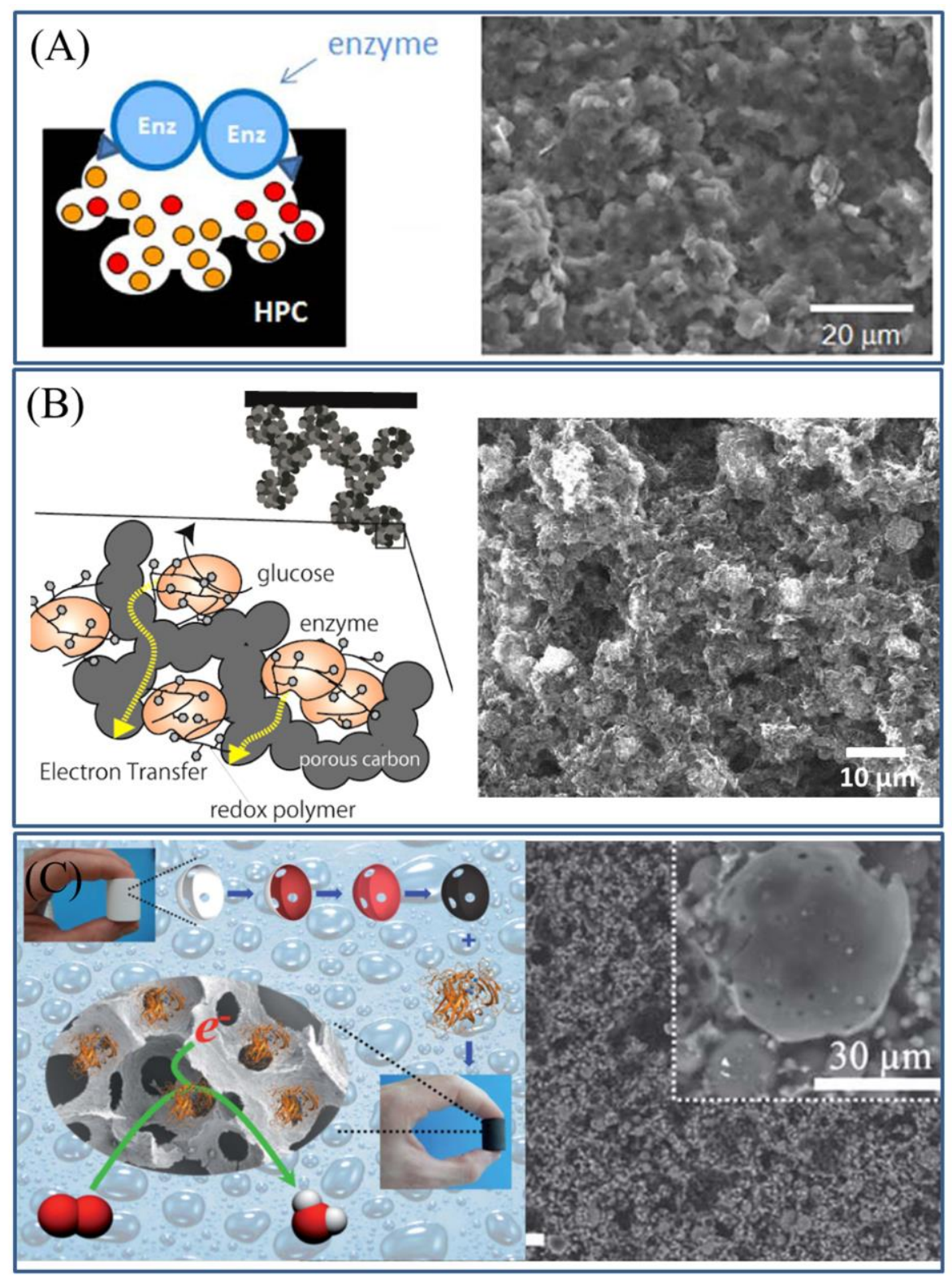

Figure 5. (A) The surface of a hierarchical porous carbon (from carbonized rice husks) anode was imaged by SEM. (B) Schematic illustration of a hierarchical porous carbon (by the EPD method) based glucose bioanode (left) and its SEM image (right). (C) Photos and SEM images of carbonaceous micro/macrocellular foams from hard macrocellular silica Si(HIPE) template. Reproduced from Ref. 39-41. 


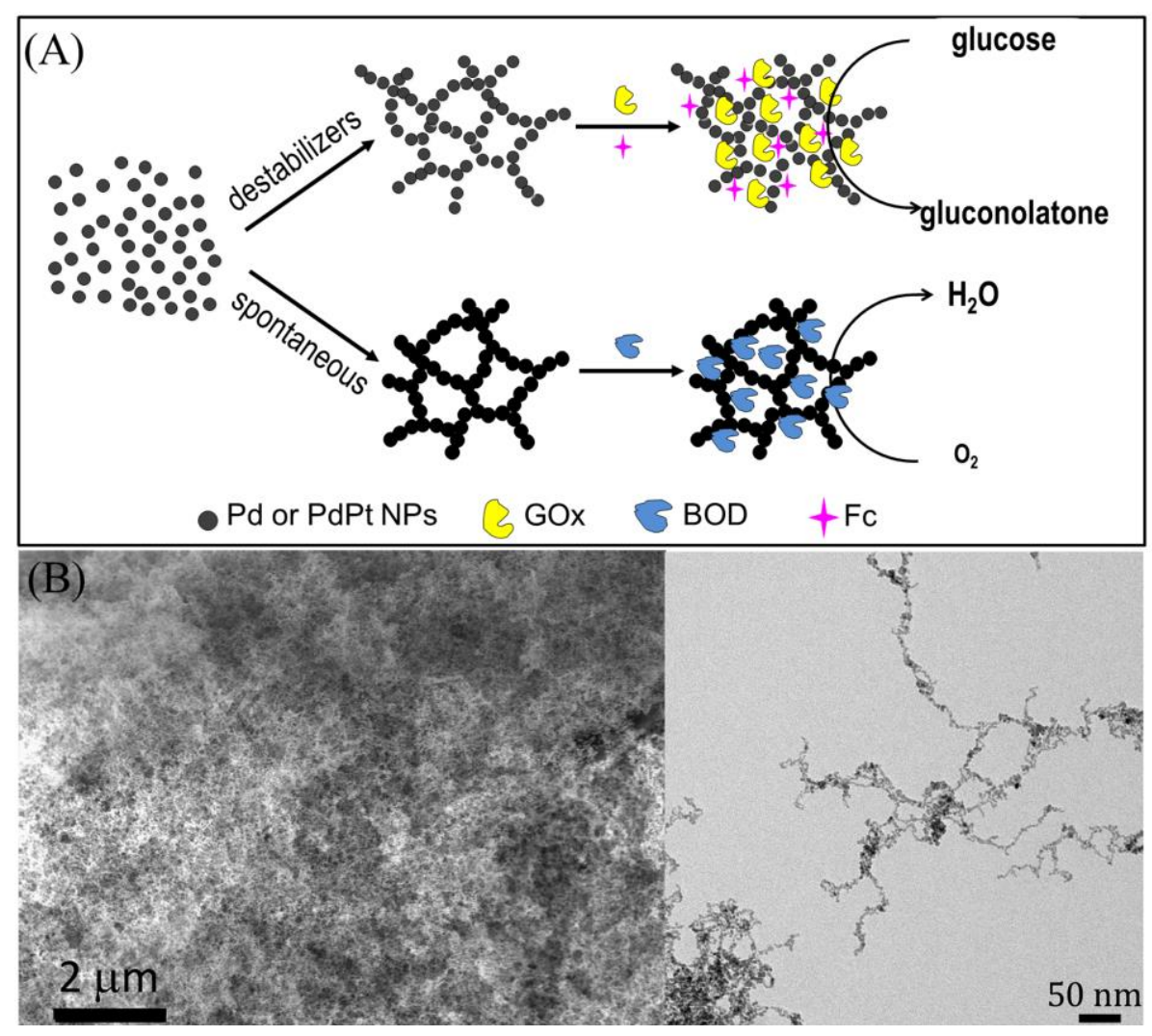

Figure 6. (A) Schematic illustration of the Pd-based aerogel formation and corresponding bioelectrodes for the Pd aerogel based EBFC. (B) Electron microscopy images of the Pd-Fc aerogel. Reproduced from Ref. 47. 

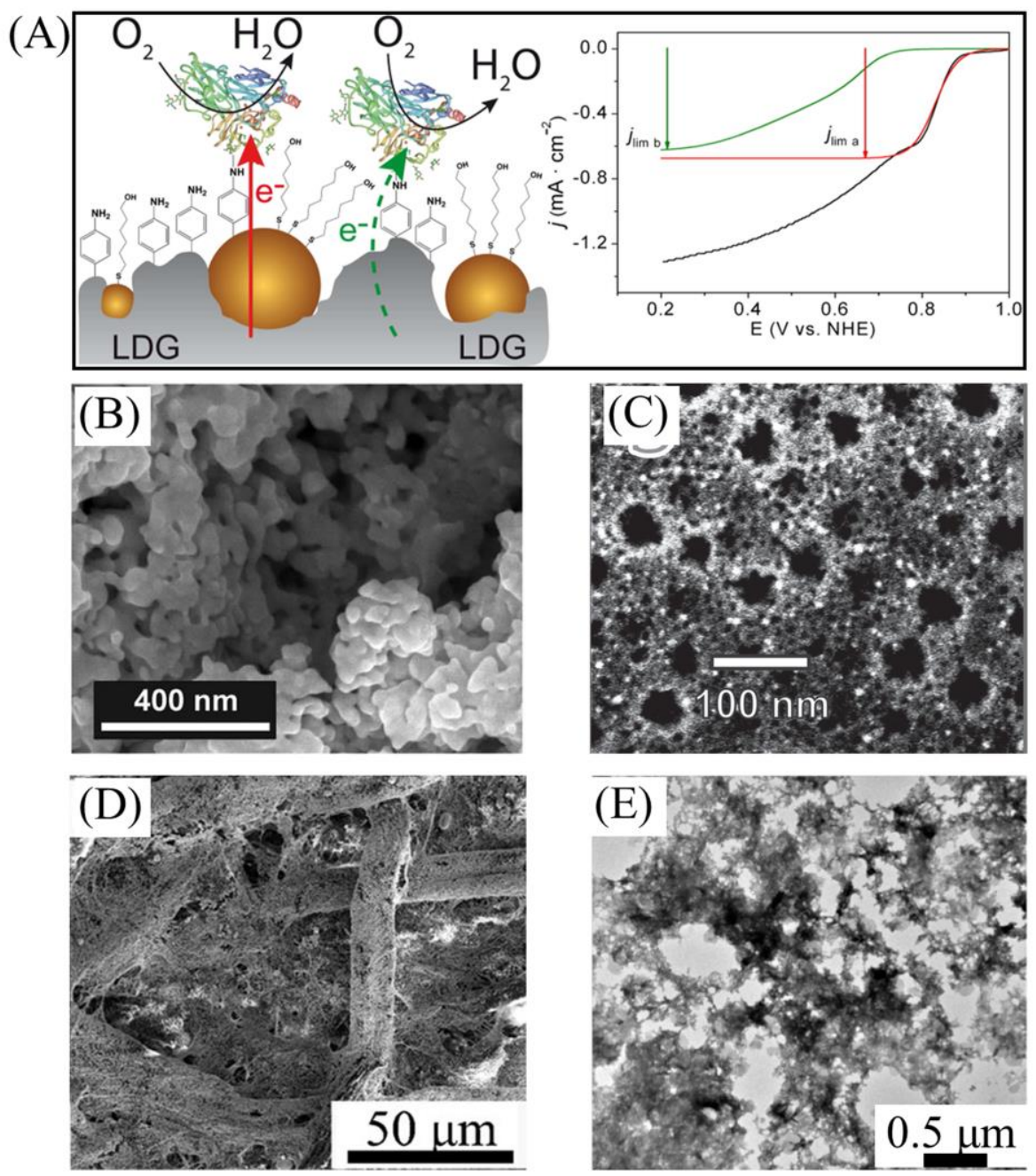

Figure 7. (A) Au NPs modified a porous low density graphite (LDG) for DET-based laccase bioelectrodes; SEM images of AuNPs modified microelectrodes (B), hierarchical mesoporous film after infiltration with Ag NPs (C), AuNPs on the surfaces of the cellulose fibers in PAE after $10 \mathrm{~min}$ of growth (D), and Au NPs-Coated M13 Bacteriophage (E). Reproduced from Ref. 48-50 and 52.
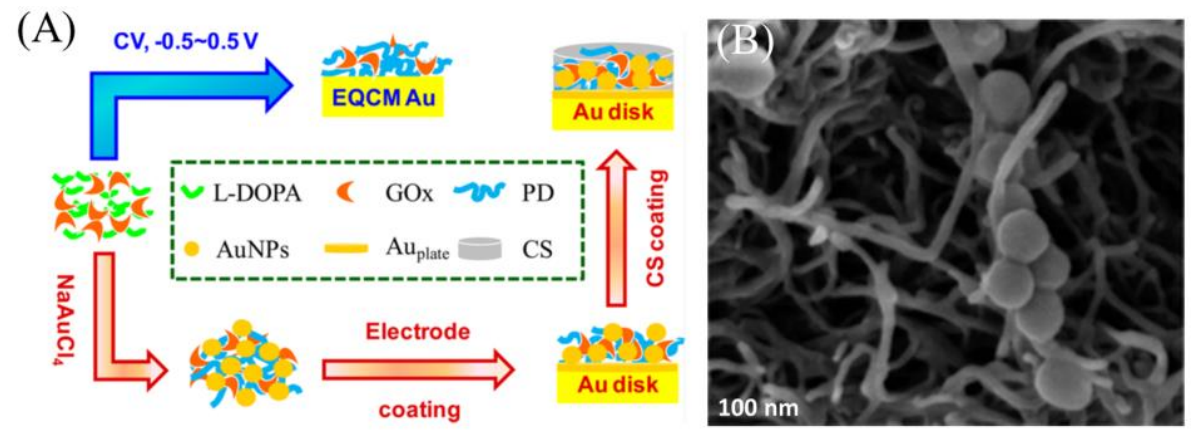

Figure 8. (A) Illustration of GOx immobilization into the Au-poly (L-DOPA) matrix as a bioanode. (B) SEM image of a cross-section of chitosan-CNT-laccase. Reproduced from $58 b, c$. 


\section{The table of contents entry}

Recent progress in enzymatic biofuel cells (EBFCs) based on porous nanostructures from carbon, noble metal, and polymer are discussed and highlighted, where the high performance of EBFCs is realized through the enhanced bioelectrocatalysis from both the electron transfer and the mass transport benefits.

Keyword: enzymatic biofuel cells, porous nanostructures, bioelectrocatalysis

Dan Wen and Alexander Eychmüller*

\section{Enzymatic Biofuel Cells on Porous Nanostructures}

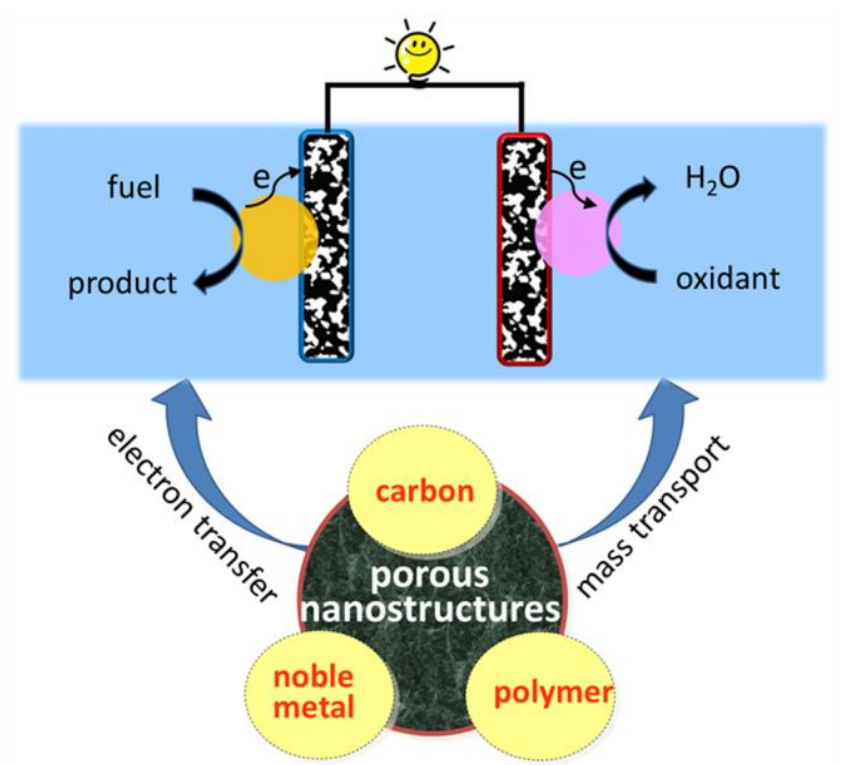

